\title{
Uma revisão dos princípios de funcionamento de células solares orgânicas
}

\author{
A review of the principles of operation of organic solar cells
}

\author{
Eduardo Henrique dos Santos Rosa ${ }^{* 1}$, Luiz Felipe Ribeiro Barrozo Toledo \\ ${ }^{1}$ Instituto de Tecnologia para o Desenvolvimento - LACTEC, Curitiba, Brasil.
}

\begin{abstract}
Recebido em 29 de Dezembro de 2020. Revisado em 09 de Março de 2021. Aceito em 15 de Março de 2021.
Esta revisão apresenta os princípios de funcionamento de células solares orgânicas (OSCs). Esta classe de dispositivos fotovoltaicos vem sendo amplamente estudada e otimizada para uma futura comercialização devido às suas características optoeletrônicas, obtendo atualmente eficiência de conversão de energia, em laboratório, comparáveis às células solares comerciais inorgânicas. Este trabalho apresenta as características de células solares orgânicas, comparando com as de outras gerações de dispositivos fotovoltaicos bem como um detalhamento dos princípios de funcionamento de OSCs, com ênfase na geração de cargas livres a partir de polímeros conjugados.
\end{abstract}

Palavras-chave: Células solares orgânicas, polímeros conjugados.

\begin{abstract}
This review presents the working principles of organic solar cells (OSCs). This class of photovoltaic devices has been extensively studied and optimized for future commercialization due to its optoelectronic characteristics, currently obtaining energy conversion efficiency, in the laboratory, comparable to commercial inorganic solar cells. This work presents the characteristics of organic solar cells compared to other generations of photovoltaic devices as well as detailing the operating principles of OSCs, with an emphasis on the generation of free charges from conjugated polymers.
\end{abstract}

Keywords: Organic solar cells, conjugated polymers.

\section{Introdução}

A produção de energia elétrica a partir da utilização de combustíveis fósseis e outras fontes não renováveis contribui de maneira significativa para o aumento da degradação ambiental [1]. O uso dessas fontes poluentes contribui para o efeito estufa 2 a partir da emissão dos gases gerados e são responsáveis pela produção de cerca de $65 \%$ do total de energia elétrica gerada 1]. Para mudar este panorama, estudos que buscam minimizar a utilização de fontes não renováveis para produção de energia elétrica ganham cada vez mais destaque. Um exemplo de fonte renovável é a que utiliza a energia solar para geração de eletricidade a partir da tecnologia de células solares.

As células solares são dispositivos fotovoltaicos que geram corrente elétrica a partir da absorção da luz do Sol e podem ser classificadas em três gerações. A primeira geração utiliza o silício (material inorgânico) como camada absorvedora de luz (camada ativa) e oferece boa eficiência de conversão de energia para uso comercial, em torno de 15\%-20\% [3]. Atualmente, a primeira geração corresponde a maior parcela no mercado de células solares [4] correspondendo à produção de cerca de $90 \%$ dos dispositivos fotovoltaicos [5]. Entretanto,

\footnotetext{
*Endereço de correspondência: eduardo-hdos@hotmail.com
}

é uma tecnologia cara devido a necessidade de se alcançar um alto grau de pureza no silício [4] para obter dispositivos eficientes. A segunda geração de células solares é conhecida como filmes finos e assim como a primeira geração utiliza materiais inorgânicos [6] como camada ativa, mas possui uma eficiência mais baixa que as células solares da geração anterior. A terceira geração são as células solares baseadas em polímeros conjugados (orgânicas), perovskitas, sensibilizadas por corante e híbridas orgânico-inorgânico [7]. Esta geração possui características atrativas para a comunidade científica como: flexibilidade [8, 9], transparência [10, custo reduzido de produção [8, 11], e boa absorção da camada ativa [8]. Entretanto, possuem problemas relacionados à degradação [12, 13, inviabilizando sua produção em larga escala para uso comercial, fazendose necessário estudos focados para a otimização dessa classe de dispositivos fotovoltaicos. Neste trabalho, é apresentado uma revisão dos princípios de funcionamento de células solares orgânicas, conhecidas como OSCs (do inglês - Organic Solar Cells), que atualmente já alcançam eficiência em laboratório na ordem de 18\% 14. Em um curto período a eficiência das OSCs obteve um avanço significativo, justificando as massivas pesquisas nesta classe de dispositivos, como ilustrado na Figura 1 a partir dos dados fornecidos no site do National Renewable Energy Laboratory (NREL) [14]. 


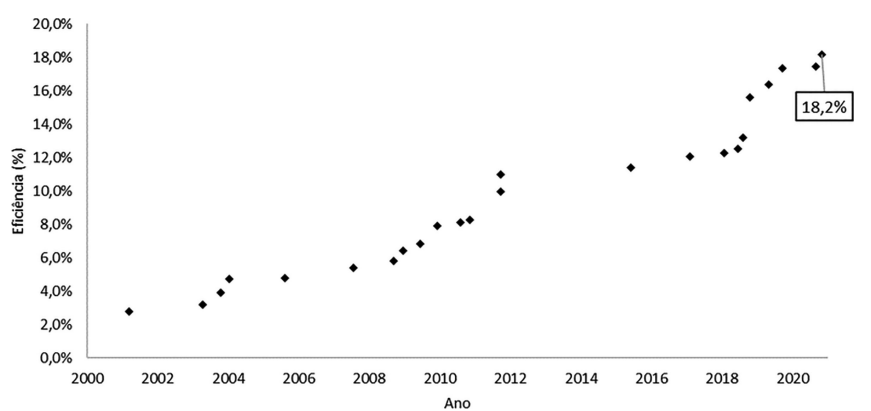

Figura 1: Progresso de eficiência de células solares orgânicas ao longo dos anos.

\section{Energia Solar}

O Sol fornece para a Terra, em uma hora do dia, energia equivalente à consumida pela humanidade durante um ano, cerca de $4,3 \times 10^{20}$ Joules [15]. Além de ser uma inesgotável e abundante fonte de energia, a energia solar não tem custos para ser captada, o que a torna atraente aos olhos dos pesquisadores. Fazer um bom proveito desta energia com a produção de dispositivos fotovoltaicos mais eficientes contribui para o aumento da utilização de um recurso renovável para produção de eletricidade.

As maiores intensidades luminosas do espectro solar correspondem ao comprimento de onda de luz visível, que varia de 400-750 nm, conforme ilustrado na Figura 2 a partir dos dados de espectro de irradiância disponibilizados no site do grupo de pesquisa McGehee [16]. Células solares que absorvam radiação solar no espectro de luz visível absorvem mais energia, sendo este um dos fatores que contribuem para se obter uma célula solar mais eficiente.

O coeficiente AM (do inglês - Air mass) relaciona a distância que a radiação solar percorre ao atravessar a atmosfera da Terra e o menor percurso que a luz do Sol faz quando está no zênite. Como forma de padronizar estudos em células solares, foi definido como espectro padrão o AM 1.5 que possui uma intensidade luminosa

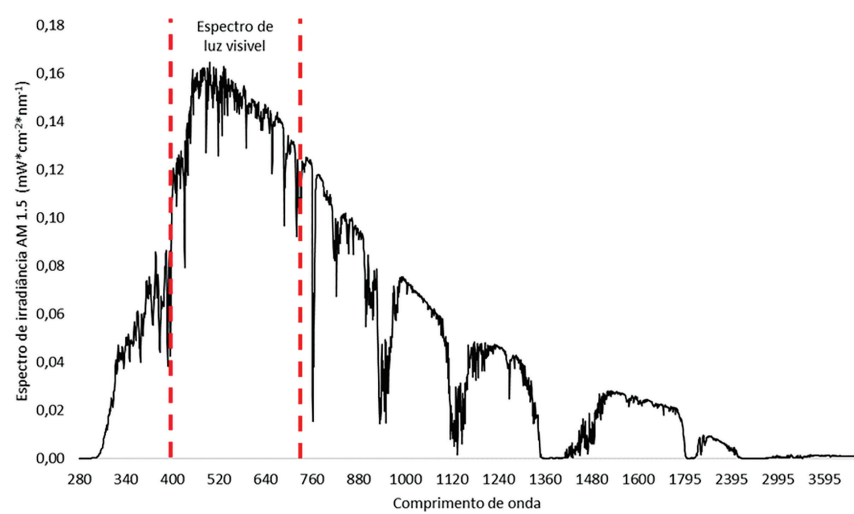

Figura 2: Espectro de irradiância AM 1.5.
$\left(I_{0}\right)$ de $100 \mathrm{~mW} / \mathrm{cm}^{2}$ e é referente ao ângulo de incidência da radiação solar de $48,2^{\circ}$ [17].

\section{Polímeros Conjugados}

As células solares orgânicas utilizam polímeros conjugados como camada ativa. Esta classe de polímeros obteve grande atenção quando, em 1977, Shirakawa e sua equipe de pesquisadores descobriram que tais polímeros possuem características semicondutoras ao dopar o polímero poliacetileno com iodo [18]. Esta descoberta resultou no prêmio Nobel de Química no ano 2000. A condutividade em polímeros conjugados ocorre devido à característica de duplas ligações alternadas (uma ligação $\pi$ e uma ligação $\sigma$ ) entre carbonos presentes na estrutura química, devido ao processo de hibridização.

O carbono em seu estado fundamental possui 4 elétrons em sua camada de valência, conforme sua distribuição eletrônica: $1 s^{2} 2 s^{2} 2 p^{2}$. A quantidade de orbitais livres semipreenchidos dita quantas ligações químicas um elemento pode fazer e no estado fundamental do carbono isto resulta em apenas duas ligações químicas. Entretanto, ao receber estímulo externo de energia, a acomodação de um elétron do subnível energético da camada $2 s$ na camada $2 p$ resulta em orbitais híbridos (hibridização), criando quatro orbitais livres semipreenchidos. A acomodação deste elétron pode ocorrer de três formas distintas: $s p, s p^{2}$ e $s p^{3}$, conforme ilustrado na Figura 3 A configuração de menor energia é a $s p^{2}$ [19], sendo esta configuração a mais comum. Quando ocorre a ligação química entre dois carbonos com hibridização $s p^{2}$ ocorre a sobreposição dos orbitais $p_{z}$ formando uma ligação pi $(\pi)$ e os elétrons dos orbitais $s p^{2}$ fazem ligações sigma $(\sigma)$, conforme ilustrado na Figura 4 .

A sobreposição dos orbitais $p_{z}$ gera orbitais moleculares ocupados, conhecidos como ligantes $(\pi)$ e orbitais desocupados chamados de antiligantes $\left(\pi^{*}\right)$. A diferença energética entre estes orbitais é conhecida como gap, que para polímeros conjugados varia de 1,0-3,0 eV [19]. O orbital $\pi$ é o orbital mais alto ocupado, sendo conhecido como HOMO (do inglês - Highest Occupied Molecular Orbital) e o orbital $\pi^{*}$ é conhecido como LUMO (do inglês - Lowest Unoccupied Molecular Orbital) [20, 21]. Os orbitais $\pi$ criados fornecem aos polímeros conjugados

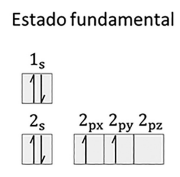

Estado excitado
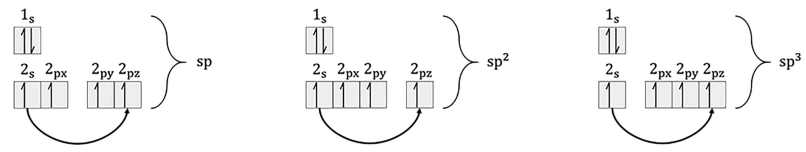

Figura 3: Hibridização do carbono. 


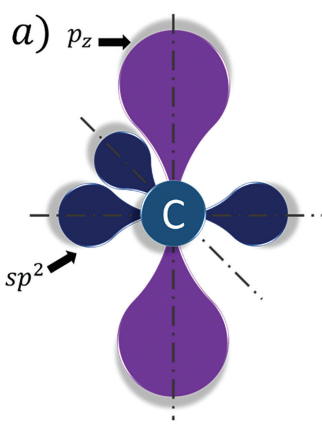

b)

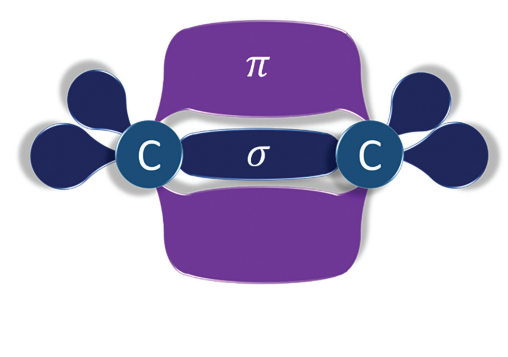

Figura 4: a) carbono com hibridização $\mathrm{sp}^{2}$ e b) Ligação entre carbonos com hibridização $\mathrm{sp}^{2}$. a)

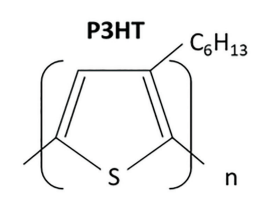

b)

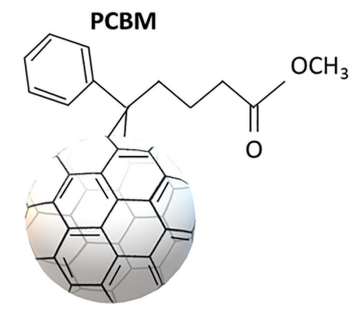

Figura 5: Estrutura química da camada ativa (P3HT:PCBM); a) P3HT e b) PCBM.

a característica de conduzir cargas no material, devido ao seu caráter semicondutor.

Uma camada ativa muito utilizada em pesquisas de OSCs utiliza os polímeros conjugados P3HT:PCBM [22 24], ilustrado na Figura 5. Onde o P3HT (poli(3hexiltiofeno (rr-P3HT))) é o material doador de elétrons e o PCBM (butirato de metilado fenil-C60) o aceitador de elétrons.

$\mathrm{Na}$ Figura 5 é possível visualizar a característica de duplas ligações alternadas entre carbonos em polímeros conjugados.

\section{Estrutura de uma OSC}

Uma célula solar orgânica em seu formato mais simples possui em sua estrutura dois eletrodos com um semicondutor orgânico como camada ativa (polímero conjugado) entre eles. Esta estrutura, com apenas um material como camada ativa, chama-se monocamada. O primeiro eletrodo (ânodo) possui a característica de ser transparente, possibilitando a passagem de luz para que os fótons possam ser absorvidos pela camada ativa do dispositivo. Para esta função, geralmente são utilizados o ITO (óxido de índio estanho), TO (óxido de estanho) ou FTO (óxido de estanho dopado com flúor). O segundo eletrodo (cátodo) é metálico e além de capturar as cargas livres geradas no dispositivo, contribui para a reflexão da luz que passa pela camada ativa, aumentando as chances de a camada ativa absorver fótons e gerar cargas livres. A diferença da função trabalho entre os eletrodos (ânodo

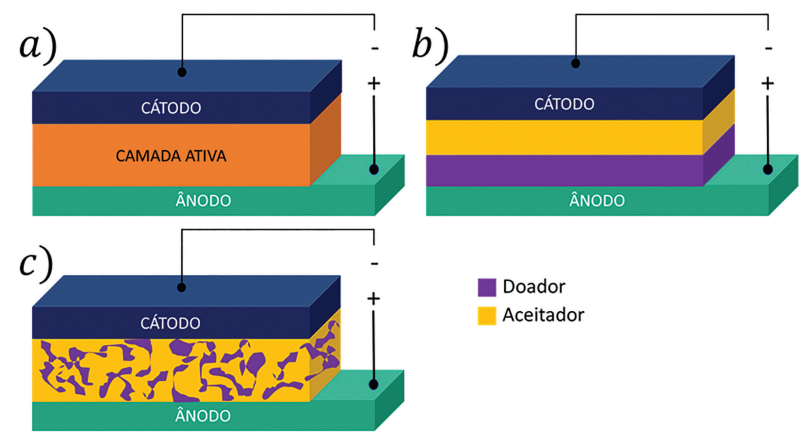

Figura 6: a) Dispositivo monocamada, b) Dispositivo bicamada c) Dispositivo BHJ.

e cátodo) gera um campo elétrico interno na célula solar que auxilia no processo de geração de cargas livres.

Existem variações estruturais na camada ativa de OSCs. A Figura 6 ilustra três variações que podem ocorrer. Dispositivos monocamada possuem sua eficiência comprometida devido à alta taxa de recombinação entre o par elétron-buraco [19. A camada ativa pode ser composta por mais de um polímero conjugado ou polímero conjugado/molécula. É o caso de dispositivos bicamada e heterojunção de volume também chamado de BHJ (do inglês - bulk heterojunction). A disposição bicamada e BHJ aumentaram significativamente a eficiência das OSCs desde que foram reportadas [25]. Dispositivos bicamada possuem dois polímeros conjugados ou polímero conjugado/molécula superpostos na camada ativa, sendo um o material doador de elétrons e o outro o aceitador de elétrons. A diferença de níveis energéticos entre o LUMO do doador e o LUMO do aceitador facilita a dissociação do par elétron-buraco para que os elétrons livres gerados possam ser capturados pelo cátodo [26]. A configuração BHJ é a estrutura que tem apresentado maiores resultados de eficiência para OSCs até então [27, 28, um dos fatores que contribuíram para isso é o fato do aumento de interfaces entre o material doador e aceitador, facilitando a dissociação de cargas. Estruturas BHJ possuem como camada ativa uma blenda polimérica, ou seja, a mistura entre dois materiais sem que haja ligação química entre eles.

Além dos eletrodos e da camada ativa, uma OSC pode conter outras camadas que auxiliam no processo de dissociação de éxcitons e transporte de cargas livres no dispositivo a partir da diferença de níveis energéticos entre camada ativa e estas camadas, conhecidas como camadas buffer. É essencial a utilização de camadas buffer para obter dispositivos mais eficientes [11]. As camadas buffer podem ser do tipo transportadora de buracos, conhecidas como HTL (do inglês - Hole transport layer) [29], disposta entre o ânodo e camada ativa, auxiliando na captura de buracos ou do tipo transportadora de elétrons, chamada de ETL (do inglês Electron transport layer) [30, disposta entre camada ativa e cátodo, auxiliando na captura de elétrons. 


\section{Geração de Cargas Livres em uma OSC}

Quando um fóton atinge um elétron presente no HOMO do polímero conjugado este elétron entra em um estado excitado. Caso a energia absorvida pelo elétron seja igual ou superior ao gap do polímero conjugado, o elétron $\left(e^{-}\right)$migra de HOMO para o LUMO. Este processo cria uma lacuna, conhecida como buraco $\left(h^{+}\right)$ no HOMO, onde o elétron estava presente. O elétron migrado e a lacuna criada estão fortemente ligados por forças de Coulomb 21. O par elétron-buraco é chamado de éxciton. Após a criação do éxciton, duas situações distintas podem ocorrer: dissociação e recombinação. O processo de recombinação ocorre quando o elétron migrado para a região do LUMO retorna para o HOMO, não havendo a dissociação do éxciton. Na recombinação o elétron decai emitindo um fóton com menor energia à que foi absorvida ou fornece energia ao sistema na forma de vibração molecular [26]. O processo de dissociação ocorre quando o elétron que está no LUMO torna-se uma carga livre após a "quebra" da ligação entre o parelétron buraco. Esta "quebra" ocorre devido à diferença entre níveis energéticos da camada ativa e eletrodos para dispositivos monocamada e pela diferença de níveis energéticos entre doador e aceitador para dispositivos bicamada e BHJ, ilustrado na Figura 7. O fato de um éxciton se dissociar não garante que o elétron seja capturado pelo cátodo e contribua para a criação de corrente elétrica em uma OSC. Isso ocorre, pois, a carga livre pode se recombinar com outras lacunas durante seu deslocamento até o cátodo.

\section{Caracterização Elétrica}

As OSCs, quando expostas à iluminação, possuem comportamentos específicos. A partir da análise desses comportamentos é possível extrair alguns parâmetros elétricos que fornecem informações sobre a performance do dispositivo construído. A curva característica de densidade de corrente pela tensão aplicada $(\mathrm{JxV})$, ilustrada na Figura 8, fornece parâmetros como densidade de corrente de curto-circuito $\left(J_{\mathrm{sc}}\right)$, tensão de circuito aberto $(V \mathrm{oc})$ e fator de forma $(\mathrm{FF})$.
A densidade de corrente de curto-circuito $\left(J_{\mathrm{sc}}\right)$ é a corrente gerada pelo dispositivo apenas pela absorção dos fótons incidentes, sem nenhuma tensão aplicada. A tensão de circuito aberto ( $V$ oc) é a diferença de potencial entre os eletrodos da célula solar para dispositivos monocamada e é relacionada ao HOMO do material doador de elétrons e o LUMO do material aceitador de elétrons para dispositivos bicamada e BHJ, onde HOMO e LUMO apresentam valores em eV [31]:

$$
V \mathrm{oc}=\frac{1}{q}\left(H O M O_{\text {doador }}-L U M O_{\text {aceitador }}\right)-0,3,
$$

sendo $q$ a carga elétrica elementar.

O fator de forma é a razão entre a potência máxima que o dispositivo fornece e o produto $V o c J_{s c}$, descrito

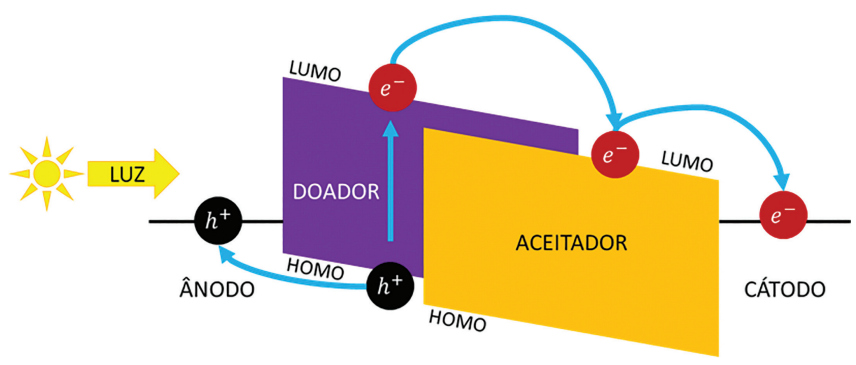

Figura 7: Níveis de energia em um dispositivo bicamada e BHJ.

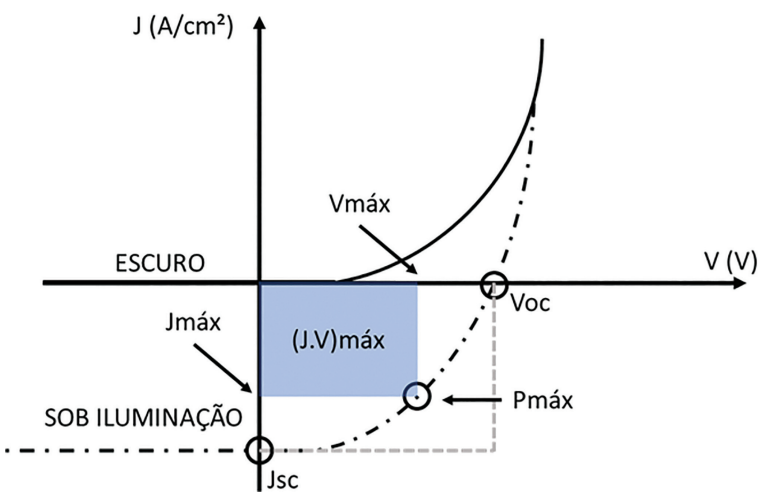

Figura 8: Curva característica JxV para um dispositivo no escuro e sob iluminação.

Tabela 1: Parâmetros elétricos e eficiência de OSCs disponíveis na literatura de acordo com sua estrutura.

\begin{tabular}{|c|c|c|c|c|c|c|}
\hline Ânodo & Camada Ativa & Cátodo & $\operatorname{Voc}(\mathrm{V})$ & $\mathrm{Jsc}\left(\mathrm{mA} \cdot \mathrm{cm}^{2}\right)$ & FF (\%) & $\eta(\%)$ \\
\hline Vidro/ITO & P3HT:PCBM & $\mathrm{Ca} / \mathrm{Al}$ & 0,641 & 8,42 & 67,8 & 3,66 \\
\hline Vidro/ITO/PEDOT:PSS & P3HT:PCBM & $\mathrm{LiF} / \mathrm{Al}$ & 0,62 & 10,88 & 67 & 4,52 \\
\hline Vidro/PEDOT:PSS & P3HT:PCBM & $\mathrm{Ca} / \mathrm{Al}$ & 0,627 & 9,73 & 53,5 & 3,27 \\
\hline Ag/PEDOT:PSS & P3HT:PCBM & $\begin{array}{l}\text { C60-SAM/ZnO- } \\
\text { NPs/ITO/Vidro }\end{array}$ & 0,62 & 10,25 & 66,6 & 4,2 \\
\hline Ag/PEDOT:PSS & P3HT:PCBM & $\begin{array}{l}\text { C60-SAM/ZnO- } \\
\text { NPs/PEDOT:PSS/Vidro }\end{array}$ & 0,61 & 9,41 & 53,3 & 3,08 \\
\hline
\end{tabular}


como 32]:

$$
F F=\frac{(J V)_{\max }}{V \mathrm{oc} J_{\mathrm{sc}}}=\frac{P_{\max }}{V \mathrm{oc} J_{\mathrm{sc}}} .
$$

A partir do fator de forma, é possível obter a performance da célula solar com o cálculo de eficiência de conversão de energia, que relaciona a potência máxima gerada pela célula solar com a potência incidente $\left(I_{0}\right)$ no dispositivo, descrito como [33]:

$$
\eta=\mathrm{FF} \frac{V \mathrm{oc} J_{\mathrm{sc}}}{I_{0}} .
$$

Uma simples variação na espessura das camadas e na mudança dos materiais de uma OSC contribui para uma alteração dos parâmetros elétricos e consequentemente na eficiência das células solares. A Tabela 1 apresenta a eficiência e os valores de $\mathrm{FF}, V$ oc e $J_{\mathrm{sc}}$ de OSCs para diferentes estruturas retiradas do livro Organic and Hybrid Solar Cells [20].

\section{Conclusões}

O poder energético do Sol aliado à sua disponibilidade, torna a tecnologia de células solares uma das mais promissoras na utilização de recursos renováveis para produção de eletricidade. O estudo de novas classes de dispositivos fotovoltaicos, como as células solares orgânicas, demonstra a importância que este tema possui, trazendo inovações e aumentando a eficiência desta tecnologia. Este trabalho apresentou um breve comparativo entre as três gerações de células solares evidenciando as principais características de cada geração seguido da explicação da intensidade luminosa a partir do espectro padronizado (AM 1.5) para testes em células solares. A geração de cargas livres em dispositivos fotovoltaicos orgânicos relaciona a absorção de energia solar pela camada ativa, composta por polímeros conjugados, com a produção de energia elétrica por parte do dispositivo, evidenciando a importância que esta classe de materiais exerce no processo de geração de fotocorrente. O cálculo de eficiência demonstra matematicamente como os parâmetros físicos das OSCs influenciam na performance destes dispositivos. As células solares orgânicas são uma promissora tecnologia que, em breve, irão fazer parte do dia a dia da sociedade ao serem implantadas nos mais diversos objetos que utilizamos no cotidiano devido às suas propriedades como: leveza, transparência, flexibilidade e custo reduzido de produção. Entender seus princípios de funcionamento é fundamental para instigar pesquisadores e futuros estudiosos da área a auxiliarem no processo de viabilização comercial desta tecnologia, contribuindo para a diversificação da matriz energética renovável mundial.

\section{Referências}

[1] D. Bogdanov, J. Farfan, K. Sadovskaia, A. Aghahosseini, M. Child, A. Gulagi, A.S. Oyewo, L.S.N.S. Barbosa e C. Breyer, Nature Communications 10, 1077 (2019).

[2] C. Nangini, A. Peregon, P. Ciais, U. Weddige, F. Vogel, J. Wang, F.M. Bréon, S. Bachra, Y. Wang, K. Gurney et al., Sci Data 6, 280 (2019).

[3] E. Raphael, M.N. Silva, R. Szostak, M.A. Schiavon e A.F. Nogueira, Quím. Nova 41, 61 (2018).

[4] X. Zou, L. Ji, J. Ge, D.R. Sadoway, E.T. Yu e A.J. Bard, Nat Commun 10, 5772 (2019).

[5] A.A. Lima, N.P. Menezes, S. Santos, B. Amorim, F. Thomazi, F. Zanella, A. Heilmann, E. Burkarter e C.A. Dartora, Revista Brasileira de Ensino de Física 42, e20190191 (2020).

[6] S. Sharma, K.K. Jain e A. Sharma, Materials Sciences and Applications 6, 1145 (2015).

[7] F. Sahli, J. Werner, B.A. Kamino, M. Bräuninger, R. Monnard, B. Paviet-Salomon, L. Barraud, L. Ding, J.J. Diaz Leon, D. Sacchetto et al., Nature materials 17, 820 (2018).

[8] N. Sadoogi, A. Rostami, B. Faridpak e M. Ferrokhifar, Engineering Science and Technology an International Journal 24, 229 (2021).

[9] Y. Sun, M. Chang, L. Meng, X. Wan, H. Gao, Y. Zhang, K. Zhao, Z. Sun, C. Li, S. Liu et al., Nat Electron 2, 513 (2019).

[10] S.B. Kang, J.H. Kim, M.H. Jeong, A. Sanger, C.U. Kim, C.M. Kim e K.J. Choi, Light Sci Appl 8, 121 (2019).

[11] C. Liang, Y. Wang, D. Li, X. Ji, F. Zhang e Z. He, Solar Energy Materials and Solar Cells 127, 67 (2014).

[12] F. Li e M. Liu, J. Mater. Chem. A5, 15447 (2017).

[13] S.K. Gupta, K. Dharmalingam, L.S. Pali, S. Rastogi, A. Singh e A. Garg, Nanomaterials and Energy 2, 42 (2013).

[14] Best Research-Cell Efficiency Chart, disponível em: ht tps://www.nrel.gov/pv/cell-efficiency.html/, acessado em $19 / 02 / 2021$.

[15] R. Foster, M. Ghassemi e A. Cota, Solar energy Renewable energy and the Environment, editado por A. Ghassemi (CRC Pess, Boca Raton, 2010).

[16] McGehee Group, Transfer Matrix Optical Modeling, disponivel em: https://web.stanford.edu/group/mcg ehee/transfermatrix/, acessado em 24/12/2020.

[17] D.J. Coutinho, Estudos sobre fotogeração, efeitos de interfaces e de transporte de portadores em células solares orgânicas. Tese de Doutorado, Universidade de São Paulo, São Paulo (2015).

[18] C.K. Chiang, C.R. Fincher Jr., Y.W. Park, A.J. Heeger, H. Shirakawa, E.J. Louis, S.C. Gau e A.G. MacDiarmid, Phys. Rev. Lett. 39, 1098 (1977).

[19] N.A.D. Yamamoto, Células Solares Orgânicas Baseadas nas Estruturas Heterojunção em Bicamada e Heterojunção de Volume. Tese de Doutorado, Universidade Federal do Paraná, Curitiba (2014).

[20] J. Lian, Y. Yuan, E. Peng, J. Huang, em: Organic and Hybrid Solar Cells, editado por H. Huang e J. Huang (Springer, New York, 2014). 
[21] G. Li, L. Liu, F. Wei, S. Xia e X. Qian, IEEE Journal of Photovoltaics 2, 320 (2012).

[22] J. Munshi, T. Chien, W. Chen e G. Balasubramanian, Soft Matter 16, 6743 (2020).

[23] H. Kaçuş, M. Biber e Ş. Aydoğan, Appl. Phys. A126, $817(2020)$.

[24] L. Jhamba, D. Wamwangi e Z. Chiguvare, Optical and Quantum Electronics 52, 245 (2020).

[25] C.W. Tang, Appl. Phys. 48, 183 (1986).

[26] C.D. Canestraro, Dispositivos fotovoltaicos orgânicos: estudo de camadas ativas e eletrodos. Tese de Doutorado, Universidade Federal do Paraná, Curitiba (2010).

[27] Y. Zhang, B. Kan, Y. Sun, Y. Wang, R. Xia, X. Ke, Y.Q.Q. Yi, C. Li, H.L. Yip, X. Wan et al., Adv. Mater. 30, 1 (2018).

[28] Y. Lin, Y. Firdaus, F.H. Isikgor, M.I. Nugraha, E. Yengel, G.T. Harrison, R. Hallani, A. El-Labban, H. Faber e C. Ma, ACS Energy Lett. 5, 2935 (2020).

[29] X. Sun, D. Zhao e Z. Li, Chinese Chemical Letters 29, 219 (2018).

[30] S. Zheng, G. Wang, T. Liu, L. Lou, S. Xiao e S. Yang, Sci. China Chem. 62, 800 (2019).

[31] T. Ameri, G. Dennler, C. Lungenschmied e C.J. Brabec, Energy Environ. Sci. 2, 347 (2009).

[32] G. Li, L. Liu, F. Wei, S. Xia e X. Qian, IEEE, Journal of Photovoltaics 2, 320 (2012).

[33] N.D.M. Said e L.C. Woon, International Journal of Advanced Research in Technology and Innovation 1, 64 (2019). 